\title{
P-Rex1 directly activates RhoG to regulate GPCR-driven Rac signalling and actin polarity in neutrophils
}

\author{
George Damoulakis ${ }^{1, *}$, Laure Gambardella ${ }^{1}$, Kent L. Rossman ${ }^{2}$, Campbell D. Lawson ${ }^{1}$, Karen E. Anderson ${ }^{1}$, \\ Yoshinori Fukui ${ }^{3}$, Heidi C. Welch ${ }^{1}$, Channing J. Der ${ }^{2}$, Len R. Stephens ${ }^{1, \pm}$ and Phillip T. Hawkins ${ }^{1, \pm, \S}$
}

\begin{abstract}
G-protein-coupled receptors (GPCRs) regulate the organisation of the actin cytoskeleton by activating the Rac subfamily of small GTPases. The guanine-nucleotide-exchange factor (GEF) P-Rex1 is engaged downstream of GPCRs and phosphoinositide 3-kinase (PI3K) in many cell types, and promotes tumorigenic signalling and metastasis in breast cancer and melanoma, respectively. Although P-Rex1-dependent functions have been attributed to its GEF activity towards Rac1, we show that P-Rex1 also acts as a GEF for the Rac-related GTPase RhoG, both in vitro and in GPCR-stimulated primary mouse neutrophils. Furthermore, loss of either P-Rex1 or RhoG caused equivalent reductions in GPCR-driven Rac activation and Rac-dependent NADPH oxidase activity, suggesting they both function upstream of Rac in this system. Loss of RhoG also impaired GPCR-driven recruitment of the Rac GEF DOCK2, and Factin, to the leading edge of migrating neutrophils. Taken together, our results reveal a new signalling hierarchy in which $\mathrm{P}$-Rex1, acting as a GEF for RhoG, regulates Rac-dependent functions indirectly through RhoG-dependent recruitment of DOCK2. These findings thus have broad implications for our understanding of GPCR signalling to Rho GTPases and the actin cytoskeleton.
\end{abstract}

KEY WORDS: Cell signalling, Cell migration, NADPH oxidase, Neutrophil, Rho GEF, Small GTPase

\section{INTRODUCTION}

Rac proteins (Rac1, Rac2 and Rac3), a subgroup within the Rho family of small GTPases, regulate key aspects of the cytoskeletal reorganisation necessary for cell motility, migration, adhesion and morphological changes. They undergo rapid spatiotemporally co-ordinated cycles of activation and inactivation that are linked to upstream signalling pathways by several classes of guanine-nucleotide-exchange factor (GEF) (Rossman et al., 2005). Crucially, recent studies have revealed crosstalk between

${ }^{1}$ Inositide laboratory, Babraham Institute, Babraham Research Campus, Cambridge CB22 3AT, UK. ${ }^{2}$ Lineberger Comprehensive Cancer Center and Department of Pharmacology, University of North Carolina at Chapel Hill, 450 West Drive, Chapel Hill, North Carolina, USA. ${ }^{3}$ Department of Immunobiology and Neuroscience, Medical Institute of Bioregulation, Kyushu University, Fukuoka, Japan.

*Present address: Oncogene Team, Division of Cancer Biology, Institute of Cancer Research, Chester Beatty Laboratories, 237 Fulham Road, London SW3 $6 J B$, UK.

${ }^{\ddagger}$ These authors contributed equally to this work

§Author for correspondence (phillip.hawkins@babraham.ac.uk)

Received 10 March 2014; Accepted 12 March 2014 different Rho GTPase subfamilies and isoforms as key to their function in different cellular and subcellular contexts (Hung et al., 2013; Sanz-Moreno et al., 2008). In addition to cell migration during normal development and immunity, deregulation of these processes drives cancer invasion and metastasis, and there is strong evidence that mutations in Rac1 and Rac GEFs are associated with disease initiation and/or progression (Berger et al., 2012; Hodis et al., 2012; Lindsay et al., 2011; Nishihara et al., 2002; Sanz-Moreno et al., 2008).

G-protein-coupled receptors (GPCRs) are acute regulators of cell movement, but the mechanisms by which they regulate GTP/ GDP exchange on Rac proteins are still poorly understood, although several lines of evidence point to a pivotal role for PtdIns $(3,4,5) P_{3}$ generated by the class I phosphoinositide 3kinase (PI3K) signal transduction pathway (Stephens et al., 2008). P-Rex1 was identified as a PtdIns $(3,4,5) P_{3}$-dependent Rac GEF activity that is synergistically regulated by $\operatorname{PtdIns}(3,4,5) P_{3}$ and the $\beta \gamma$ subunits of receptor-coupled heterotrimeric $G$ proteins (Barber et al., 2007; Hill et al., 2005; Welch et al., 2002), and subsequent studies have assumed that this is its major catalytic function in cells. However, despite P-Rex1 being ideally placed to transduce GPCR-driven signals directly through Rac, neutrophils from P-Rex $1^{-/-}$mice display only partial defects in Rac-dependent functions (Dong et al., 2005; Welch et al., 2005). This suggests that the P-Rex1-mediated regulation of Rac signalling is more complex or context-dependent than the conceptually satisfying idea of P-Rex1 as the direct dominant link between GPCRs and Rac activation. Mutations in the related P-Rex2 gene have recently been identified as drivers of melanoma, and genetic deletion of P-Rex1 reduced metastasis of N-Ras-driven melanoma in mice (Berger et al., 2012; Lindsay et al., 2011). P-Rex2 has also been shown to inhibit the tumour suppressor and PtdIns $(3,4,5) P_{3}$ phosphatase, PTEN (Fine et al., 2009). In light of these findings, the task of understanding the biology of P-Rex family GEFs, and their control of Racdependent functions, becomes all the more pressing.

Neutrophils are an attractive model for studies into actin dynamics because they exhibit a rapid, amoeboid form of migration characteristic of many cell types, including other leukocytes, stem cells and some tumour cells (Kay et al., 2008; Sanz-Moreno et al., 2008; Stephens et al., 2008). In addition to regulating the neutrophil cytoskeleton, Rac proteins are known to be essential components of the NADPH oxidase complex, responsible for the generation of microbicidal reactive oxygen species (ROS) (Dinauer, 2003). Neutrophils respond robustly and rapidly to a variety of GPCR ligands, making them ideal for biochemical studies of GPCR-driven GEF and GTPase function in primary cells.

RhoG is a fourth member of the Rac subfamily, but does not directly interact with classical, CRIB-domain-containing Rac1, 2 
and 3 effectors. Instead, it has been reported to function upstream of Rac in some systems by recruiting a bipartite Rac GEF complex comprising members of the DOCK (isoforms 1-5) and ELMO (isoforms 1-3) families (Côté et al., 2002; Katoh and Negishi, 2003). In addition to roles in EGF-dependent cell migration, neurite outgrowth, endocytosis and leukocyte transendothelial migration, RhoG is required for efficient activation of the NADPH oxidase by GPCR ligands in mouse neutrophils (Bass et al., 2011; Condliffe et al., 2006; Hiramoto-Yamaki et al., 2010; Samson et al., 2010; van Buul et al., 2007). Furthermore, mouse neutrophils lacking DOCK2, the major DOCK protein in neutrophils, have severe defects in GPCR-stimulated ROS production and cell migration (Kunisaki et al., 2006).

In light of the above work, we set out to explore the relationship between RhoG and Rac activation downstream of GPCRs, using a combination of biochemical and genetic approaches. Our data suggest that, contrary to the prevailing view of its function, P-Rex1 acts as a GEF for RhoG downstream of GPCR engagement in mouse neutrophils, and regulates Racdriven processes indirectly in this system by promoting RhoGdependent recruitment of the Rac GEF DOCK2.

\section{RESULTS \\ RhoG is activated by the G-protein-coupled fMLP receptor through a PI3K $\gamma$-dependent mechanism}

There is evidence for a role of RhoG downstream of GPCR engagement in neutrophils (Condliffe et al., 2006); however, its activation and regulation has yet to be measured in any GPCRdriven system. In order to assess the regulation of RhoG downstream of GPCRs, we developed a refined procedure for purifying primary mouse neutrophils in a quiescent state that allows them to respond robustly and rapidly to GPCR ligands, such as the formylated peptide $N$-formyl-methionyl-leucylphenylalanine (fMLP), with minimal pre-activation by autocrine or paracrine factors (see Materials and Methods). Stimulation of mouse neutrophils with fMLP resulted in a rapid transient rise in
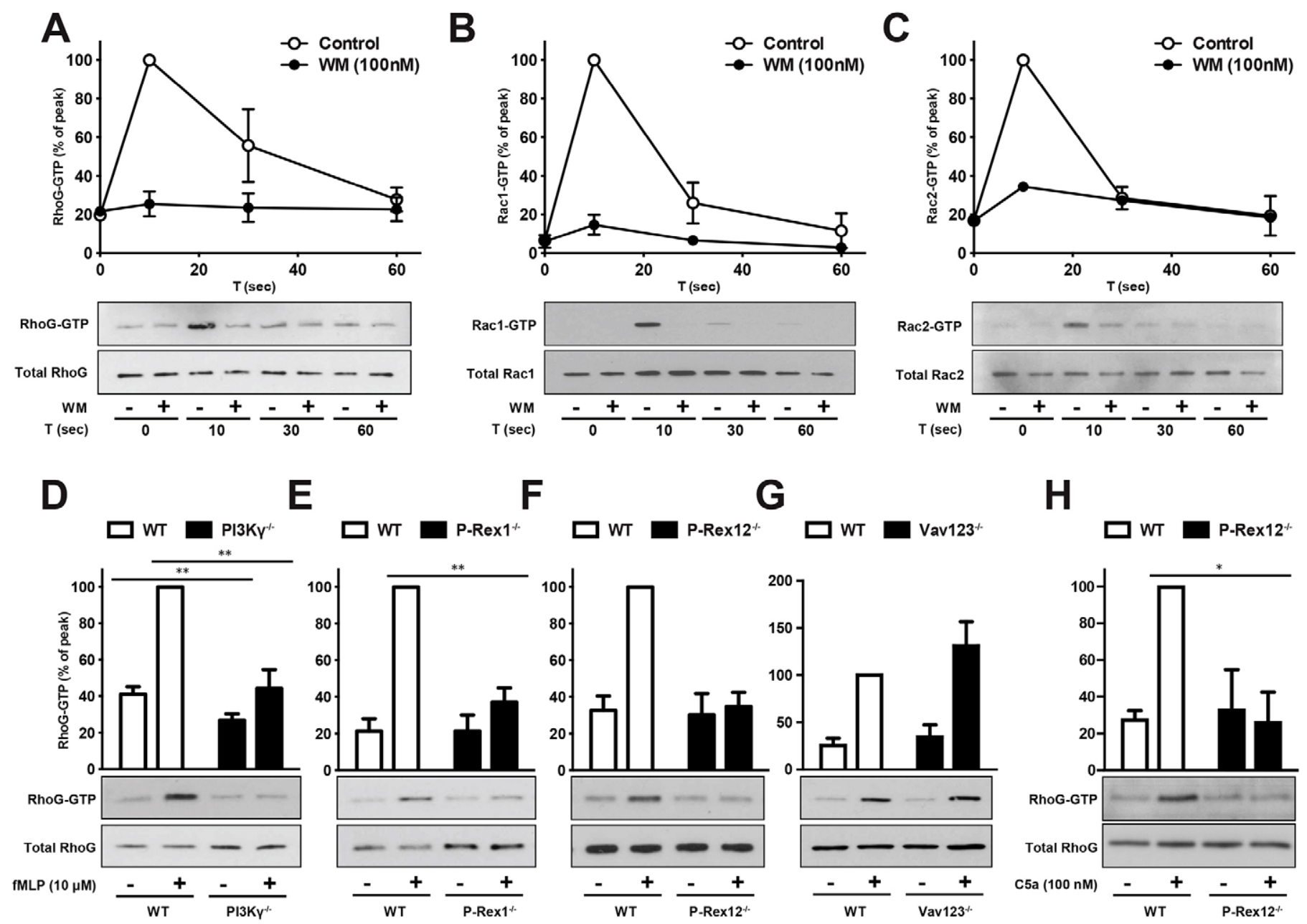

Vav123

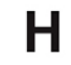

H

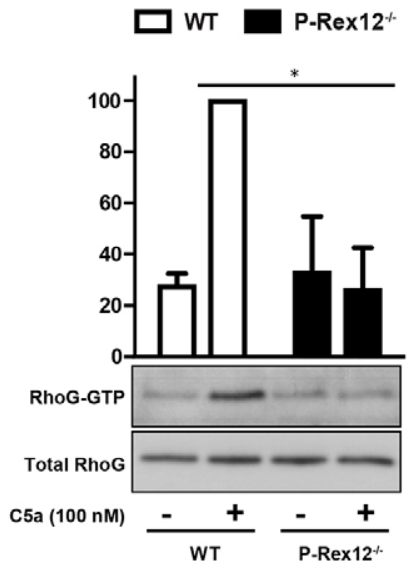

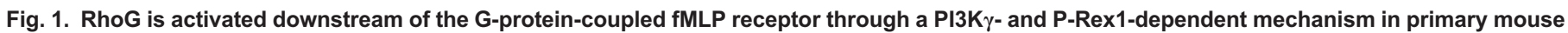

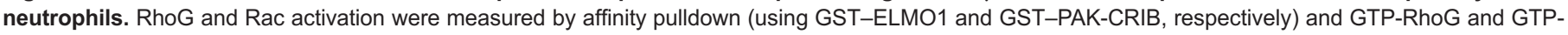

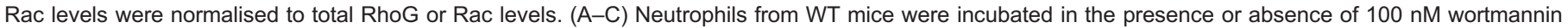
(WM), and stimulated with $10 \mu \mathrm{M}$ fMLP for the indicated times. Data are mean \pm s.e.m. of four $(A)$ and range of two (B,C) independent experiments.

(D) Neutrophils from WT and PI3K $\gamma^{-1-}$ mice were stimulated with $10 \mu \mathrm{M}$ fMLP for $10 \mathrm{~s}$. Data are mean $\pm \mathrm{s}$.e.m. of four independent experiments.

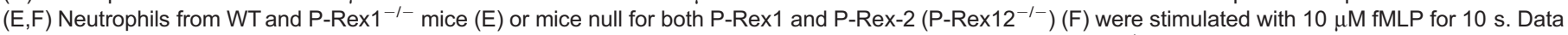

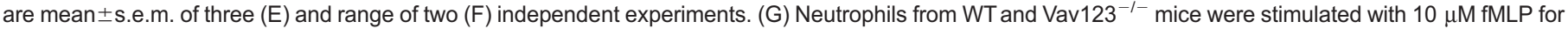

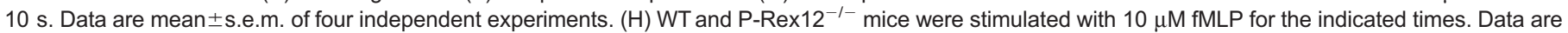
mean \pm s.d. of three independent experiments. ${ }^{*} P \leq 0.05,{ }^{* *} P \leq 0.01$, by an unpaired Student's $t$-test. 
the levels of GTP-RhoG, peaking at $10 \mathrm{~s}$ and returning to basal levels within $1 \mathrm{~min}$ (Fig. 1A). This response was acutely sensitive to the pan-PI3K inhibitor wortmannin, suggesting GPCR-driven activation of RhoG requires PtdIns $(3,4,5) P_{3}$ synthesis by class I PI3Ks. This was supported by measurements in neutrophils from PI3K $\gamma^{-1-}$ mice, which revealed that fMLP-driven activation of RhoG was significantly dependent on PI3K $\gamma$ (Fig. 1D), consistent with previous studies identifying $\mathrm{PI} 3 \mathrm{~K} \gamma$ as the dominant class I PI3K activity downstream of GPCRs in mouse neutrophils (Hirsch et al., 2000; Li et al., 2000; Sasaki et al., 2000). Under equivalent conditions, fMLP-stimulated formation of GTP-Rac1 and -Rac2 exhibited similar kinetics and wortmannin-sensitivity as did formation of GTP-RhoG (Fig. 1B,C), suggesting these responses might be linked.

\section{P-Rex1 is required for fMLP-driven activation of RhoG}

Certain GEFs for Rac have been identified as GEFs for RhoG in other cell systems, including members of the Vav family (Samson et al., 2010). P-Rex1 and Vav1 have also been identified as major regulators of fMLP-stimulated Rac1/2 activation in neutrophils (Lawson et al., 2011; Welch et al., 2005), and therefore we investigated the role of these two GEF families in the regulation of RhoG. Strikingly, we found that loss of P-Rex1 (P-Rex $1^{-/}$) severely impaired fMLP-driven RhoG activation (Fig. 1E), whereas loss of all three Vav isoforms had no significant effect (Fig. 1G). The major isoform of P-Rex in mouse neutrophils is PRex1, with no functional role previously identified in these cells for P-Rex2 (Donald et al., 2004). Consistent with this, neutrophils with loss of both P-Rex1 and P-Rex2 displayed a defect in RhoG activation similar to that seen in neutrophils from P-Rex $1^{-/-}$mice (Fig. 1F).

Neutrophils express high levels of many GPCRs allowing them to respond rapidly to a variety of stimuli. To assess whether the dependence of RhoG activity on P-Rex is a more general feature of GPCR signalling in neutrophils, or specifically downstream of the fMLP receptor, we treated mouse neutrophils with the complement factor $\mathrm{C} 5 \mathrm{a}$, a potent inflammatory mediator and neutrophil chemoattractant. Like fMLP, C5a induced rapid activation of RhoG that was strongly P-Rex-dependent (Fig. 1H).

These results suggest that P-Rex1 is upstream of RhoG activation in the pathway downstream of GPCR engagement in neutrophils. However, positive-feedback loops are known to play a role in GPCR signalling to Rho-family GTPases (Stephens et al., 2008) and can obfuscate the interpretation of signalling data. We tested the potential role of such feedback at three levels. First, we assessed whether RhoG activation required the presence of Rac2. We found that fMLP-driven RhoG activity was not reduced in neutrophils from Rac $2^{-/-}$mice (Fig. 2A), indicating that regulation of RhoG activity by P-Rex 1 is not an indirect consequence of P-Rex1 activity towards Rac2. Second, we assessed fMLP-driven class I PI3K activity. We found no difference in fMLP-stimulated $\operatorname{PtdIns}(3,4,5) P_{3}$ accumulation between wild-type (WT) and $\mathrm{RhoG}^{-/-}$mice (Fig. 2B), confirming that RhoG functions downstream of $\mathrm{PI} 3 \mathrm{~K} \gamma$ in this system. Third, we used latrunculin B to block actin polymerisation, and measured its effect on fMLP-induced RhoG activity. We observed no reduction in RhoG activation under these conditions suggesting that actin polymerisation is not required to initiate signalling through P-Rex1 or RhoG (Fig. 2C).

\section{P-Rex1 is an efficient GEF for RhoG in vitro}

Previous work has indicated that P-Rex 1 can act as a GEF for Rac proteins in vitro but its activity towards RhoG has not been reported. We therefore investigated the substrate specificity of PRex1 in vitro in more detail. We first employed a mant-GTP incorporation assay using a panel of $\mathrm{His}_{6}$-tagged Rho family GTPases as substrates for the purified P-Rex1 DH-PH domain. In this assay, P-Rex1 exhibited substantial exchange activity towards Rac1/2 and Cdc42 (Fig. 3A,B,E), as previously shown (Welch et al., 2002), as well as Rac3 (Fig. 3C), the Cdc42-like Rho protein TC10 (Fig. 3F) and, importantly, RhoG (Fig. 3D). Full-length P-Rex1 (purified from baculovirus-infected Sf9 cells)
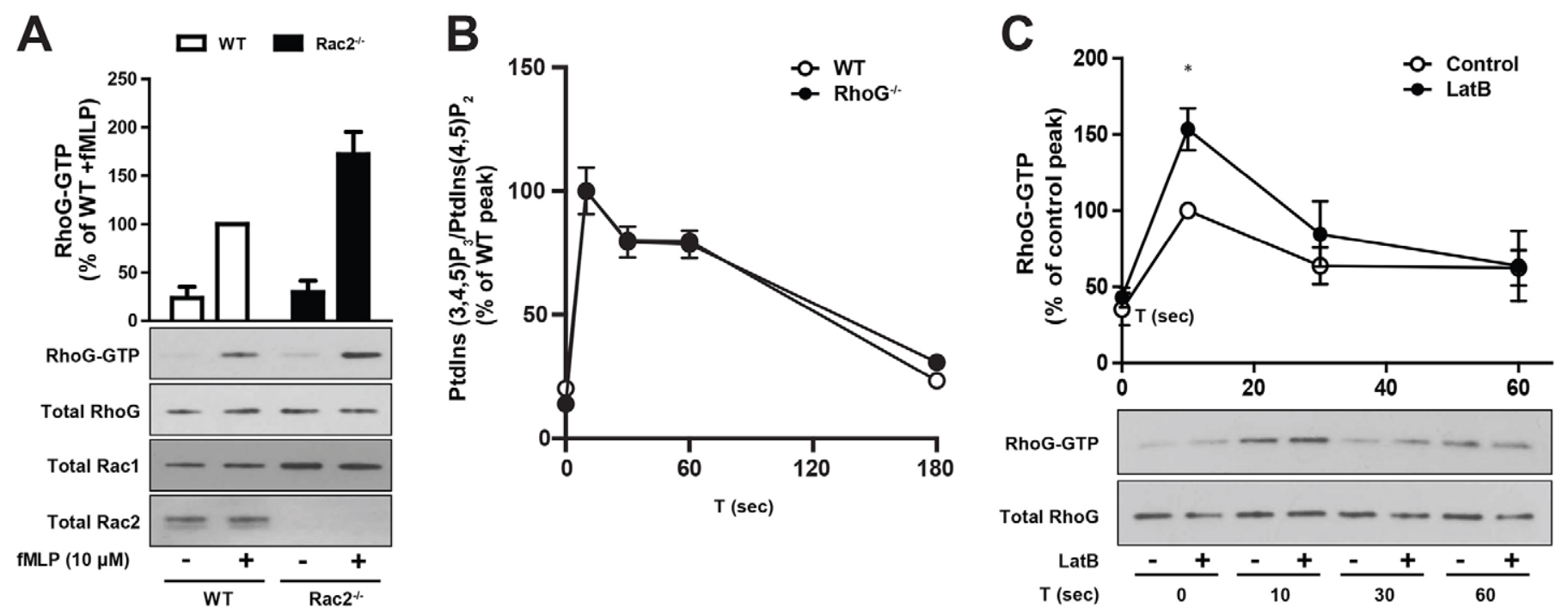

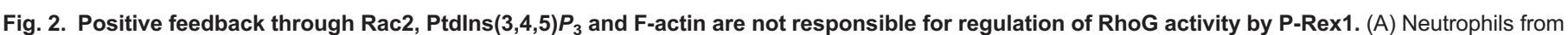
WT and Rac2 ${ }^{-1-}$ mice were stimulated with $10 \mu \mathrm{M}$ fMLP for $10 \mathrm{~s}$. RhoG activation was measured by affinity pulldown using GST-ELMO1. Data are mean \pm range of two independent experiments. (B) Ptdlns $(3,4,5) P_{3}$ was measured by LC-ESI/MS and normalised to the levels of Ptdlns $(4,5) P_{2}$. Data are

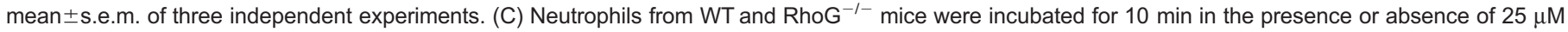

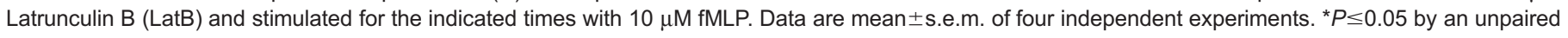
Student's $t$-test. 
A

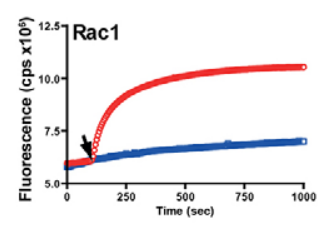

$\mathbf{F}$

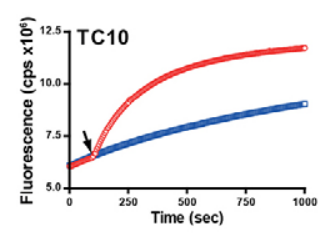

B

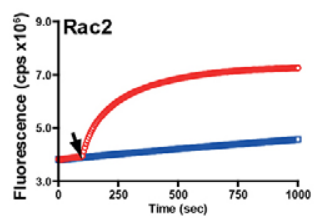

C

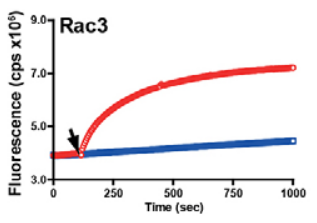

$\mathrm{H}$

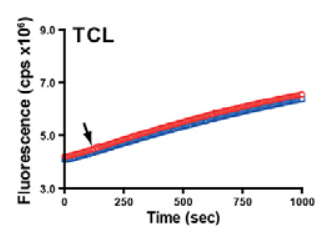

I

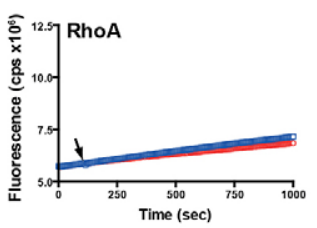

D

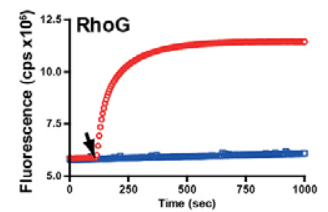

E

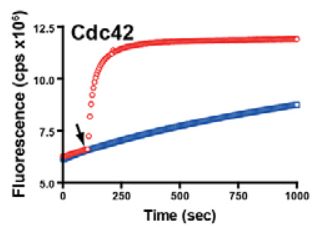

J

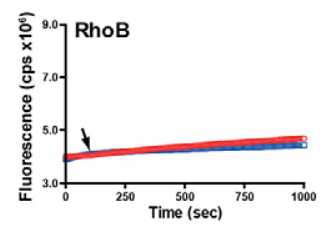

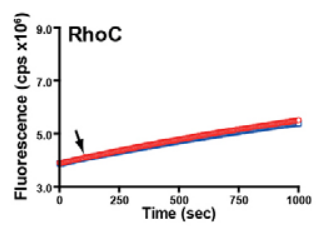

K
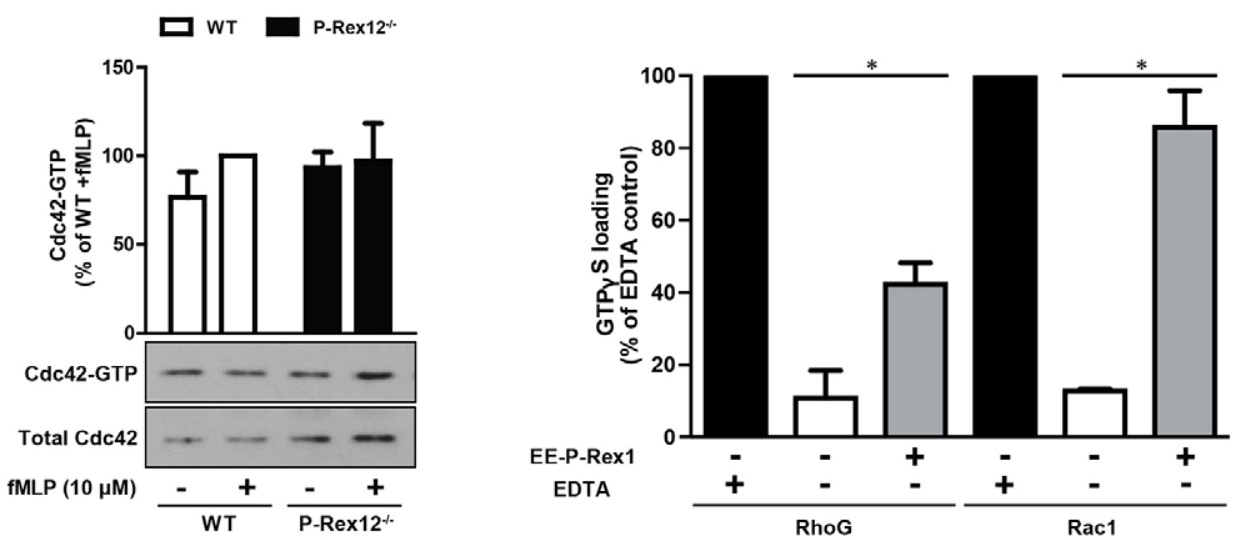

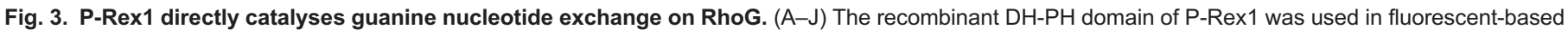

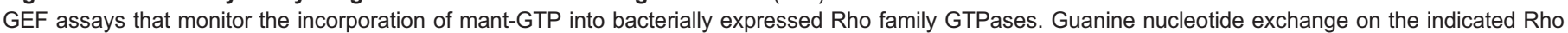

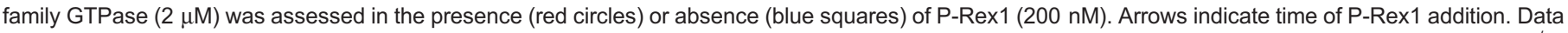

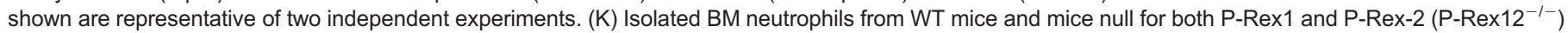
were stimulated with $10 \mu \mathrm{M}$ fMLP for $10 \mathrm{~s}$. Cdc42 activation was measured by affinity pulldown using GST-PAK-CRIB. Data are mean \pm s.e.m. of three

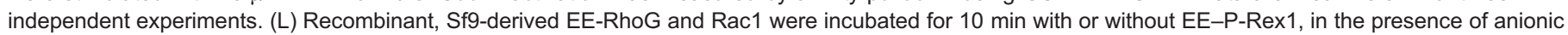
liposomes and PtdIns $(3,4,5) P_{3}$, and the incorporation of $\left[{ }^{35} \mathrm{~S}\right] \mathrm{GTP} \gamma \mathrm{S}$ was assessed by immunoprecipitation of EE-RhoG or -Rac1 and liquid scintillation

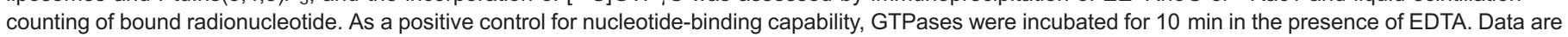
mean \pm s.e.m. of three independent experiments performed in duplicate ${ }^{*} P \leq 0.05$ by an unpaired Student's $t$-test.

was also able to act as an efficient GEF for RhoG, as well as Rac1, using an alternative assay, based on immunoprecipitation of $\left[{ }^{35} \mathrm{~S}\right] \mathrm{GTP} \gamma \mathrm{S}$-loaded and EE-tagged lipid-modified RhoG (Fig. 3L).

These results suggest that P-Rex1 has relatively broad substrate specificity and the potential to act as an efficient GEF for RhoG, Rac1, Rac2 and Rac3, Cdc42 and TC10, but not RhoA, RhoB and RhoC or TCL (Fig. 3G-J). Transcriptome analysis of mouse neutrophils suggests TC10 is not expressed in these cells (our unpublished observations). Although $\mathrm{Cdc} 42$ is known to have a role in neutrophils, we could not detect fMLP-driven Cdc42 activation under conditions where RhoG and Rac were activated, and levels of GTP-Cdc42 were unaffected in neutrophils from mice null for both P-Rex1 and P-Rex2 (Fig. 3K).

\section{P-Rex1 and RhoG regulate fMLP-driven Rac activity and NADPH oxidase}

The above data identify P-Rex1 as a dominant GEF, coupling GPCR activation directly to nucleotide exchange on RhoG. A key question, therefore, is the extent to which activation of RhoG is the most important function of P-Rex1 and, additionally, the relationship of this function to the activation of its alternative potential substrates Rac1 and Rac2. Separate studies have previously reported that RhoG and P-Rex1 regulate some Rac2dependent neutrophil functions, such as activation of the NADPH oxidase (Condliffe et al., 2006; Dong et al., 2005; Welch et al., 2005). However, the relatively small effects of P-Rex1 deletion observed in these studies contrast with the more severe defects reported upon RhoG deletion, and thus conflict with our observation that P-Rex1 is the major regulator of RhoG in this system. We reasoned that this might be explained by differences in the experimental conditions used for these studies, and sought to compare the effects of P-Rex and RhoG deletion directly in equivalent assays. Under conditions where fMLP stimulation drives P-Rex-dependent RhoG activation, neutrophils from $\mathrm{RhoG}^{-/-}$mice and mice null for both P-Rex1 and P-Rex2 displayed comparable severe defects in fMLP-driven NADPH oxidase activity (Fig. 4). These defects in ROS formation were apparent across a range of fMLP concentrations, although they were proportionately greater at lower doses. 


\section{A}

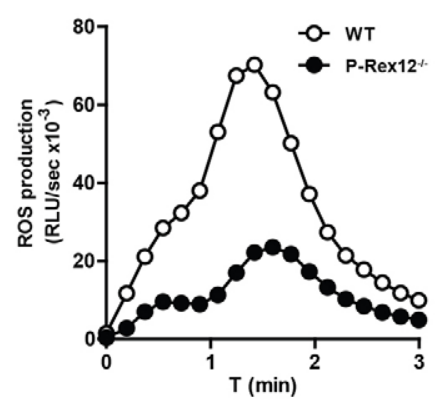

C

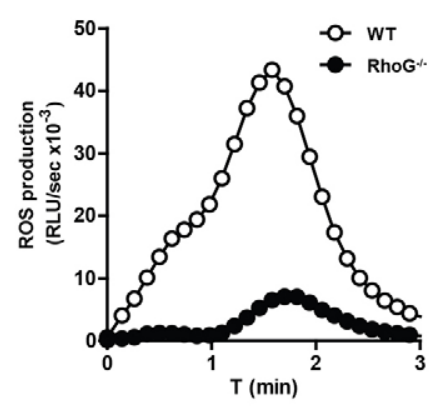

B

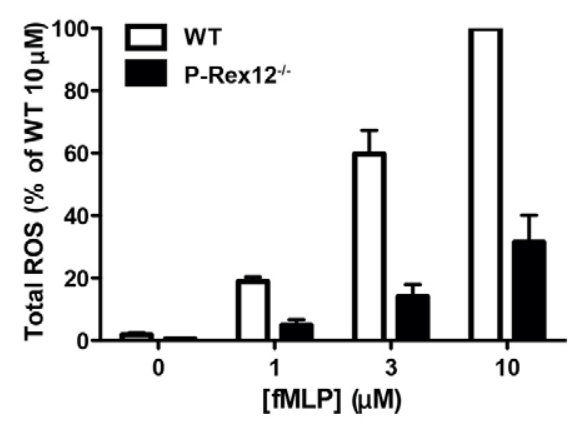

D

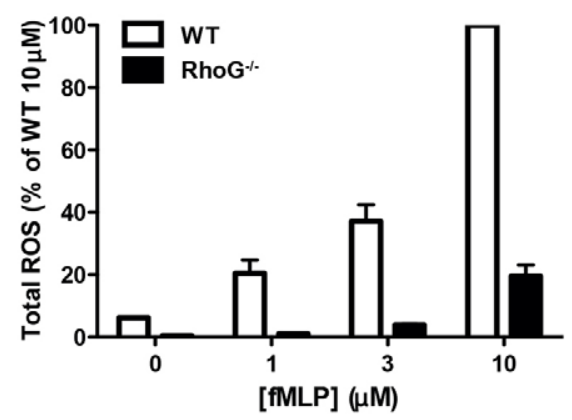

Fig. 4. RhoG and P-Rex regulate fMLP-driven NADPH oxidase activity in primary mouse neutrophils. Neutrophils from WT mice and mice null for both P-Rex1 and P-Rex-2 (P-Rex12-/- ) $(A, B)$ or RhoG $^{-1-}$ mice $(C, D)$ mice were stimulated with the indicated doses of $\mathrm{MLP}$, and production of reactive oxygen species (ROS) measured by luminol-dependent chemiluminescence in the presence of HRP. Data are presented as representative kinetic traces of the rate of ROS synthesis [relative light units (RLU) per second] from experiments using $10 \mu \mathrm{M}$ fMLP $(A, C)$, and total integrated ROS levels (B,D). Data are mean \pm s.e.m. of three $(B)$ and \pm range of two (D) independent experiments.
Stimulation of neutrophils with a sub-maximal dose of fMLP $(1 \mu \mathrm{M})$ elicited rapid formation of GTP-Rac1 and GTP-Rac2 (Fig. 5A,B) that was substantially $(\geq 50 \%)$ reduced in neutrophils from both $\mathrm{RhoG}^{-/-}$mice and mice null for both P-Rex1 and PRex2 (Fig. 5C-F). Neutrophils from mice null for all three Vav isoforms (Vav1, Vav2 and Vav3) also displayed partially reduced Rac1 (but not Rac2) activation under these conditions (Fig. 5G,H). At a higher dose of fMLP $(10 \mu \mathrm{M})$, and consistent with previously published data, the effects of RhoG and P-Rex deletion were significantly smaller (Fig. 6A-D), suggesting stimulus-strengthdependant redundancy is present in this system and that other, PRex- and/or RhoG-independent, routes to Rac activation can be engaged by the fMLP receptor. In this regard, and again consistent with previously published data (Kim et al., 2003; Lawson et al., 2011), neutrophils from mice null for all three Vav isoforms also displayed partially reduced Rac activation at $10 \mu \mathrm{M}$ fMLP (Fig. 6E,F). The equivalence in effects of RhoG or P-Rex deletion on either fMLP-stimulated formation of ROS or GTPRac1 and -Rac2, suggests that the major role for P-Rex in this signalling network is to regulate RhoG and implies that P-Rex 1 can regulate Rac1 and Rac2 indirectly in this system through an effect on RhoG. Furthermore, given the much bigger effects of RhoG deletion on ROS formation than activation of Rac1 and Rac2, they also suggest some channelling of a Rac1 and Rac2 pool to the oxidase must occur, or that some effects of P-Rex1 and/or RhoG are not through Rac1 or Rac2 alone.

\section{RhoG regulates fMLP-driven translocation of DOCK2}

We next sought to identify the mechanism by which P-Rex1 and RhoG signalling might control Rac activation in neutrophils. Of the few identified RhoG effector proteins, only those of the ELMO family have been convincingly demonstrated to mediate RhoG-dependent processes in cells (Ho et al., 2009; Katoh and Negishi, 2003). ELMO proteins exist constitutively bound to members of the DOCK family and, together, they form a bipartite GEF complex that catalyses nucleotide exchange on Rac through the DOCK DHR-2 domain (Brugnera et al., 2002; Kulkarni et al., 2011; Lu et al., 2004; Lu et al., 2005). DOCK2, a major DOCK isoform in leukocytes, has been shown to be a crucial regulator of GPCR-driven Rac activity in neutrophils (Kunisaki et al., 2006; Nishikimi et al., 2009). Using neutrophils from mice expressing a germline-encoded DOCK2-GFP transgene, the authors of those studies demonstrated that DOCK2 translocation to the plasma membrane in fMLP-stimulated neutrophils is PI3K-dependent and in part mediated by the DOCK2 DHR-1 domain known to bind PtdIns(3,4,5) $P_{3}$ (Côté et al., 2005). However, a DHR-1independent input into DOCK2 translocation, as observed in those studies, remains unaccounted for.

We reasoned that RhoG might regulate fMLP-driven Rac activity in neutrophils by promoting DOCK2 recruitment to the plasma membrane, presumably through an interaction with ELMO. We tested this hypothesis by crossing DOCK2-GFP and $\mathrm{RhoG}^{-/-}$mice, to generate DOCK2-GFP-expressing $\mathrm{RhoG}^{-/-}$mice and DOCK2GFP-expressing WT controls, and examined the translocation of DOCK2-GFP to the plasma membrane in neutrophils undergoing fMLP-induced chemokinesis on glass coverslips using spinning disc confocal microscopy. Counterstaining with the membrane dye Cell Mask Orange allowed us to control for any increases in membrane density associated with membrane ruffling.

Over the course of these experiments, we observed two discrete classes of DOCK2-GFP translocation events, which we termed 'small' and 'large'. Both WT and RhoG ${ }^{-/-}$neutrophils were able to form small DOCK2-GFP-positive protrusions (Fig. 7A,B). However, large DOCK2-GFP translocation events were only observed in WT neutrophils. These data indicate that RhoG promotes translocation of DOCK2 to the plasma membrane and thus provide a mechanistic basis for P-Rex1- and RhoG-mediated control of fMLP-driven Rac activity in neutrophils. 
$\mathbf{A}$
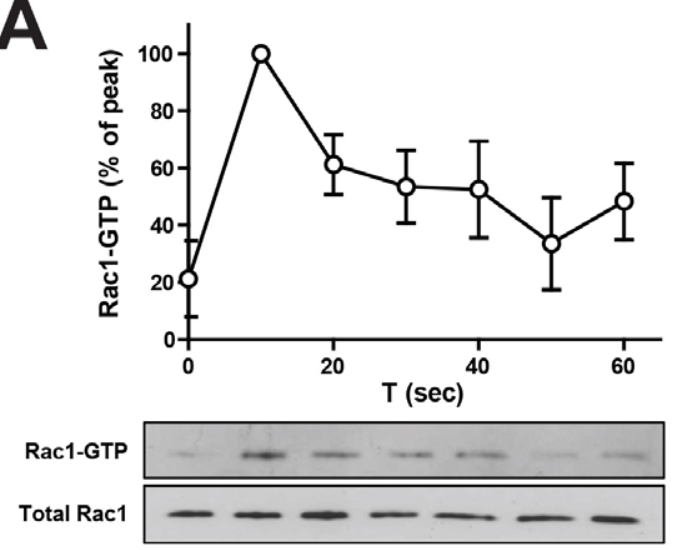

B
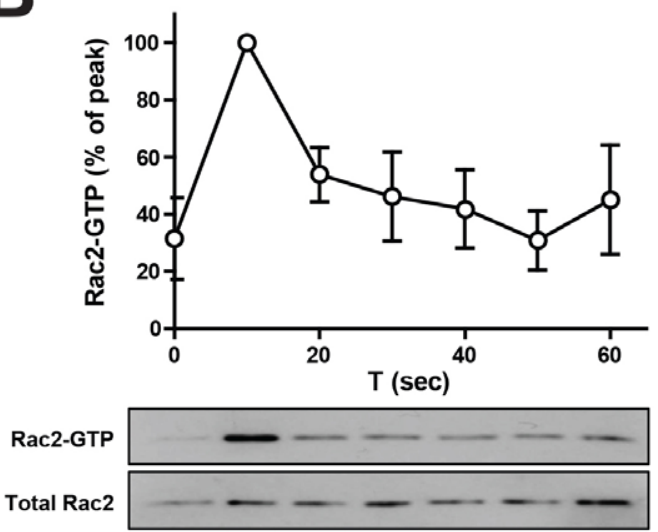

C

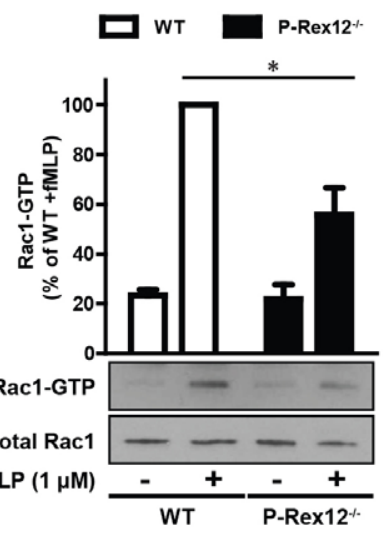

E

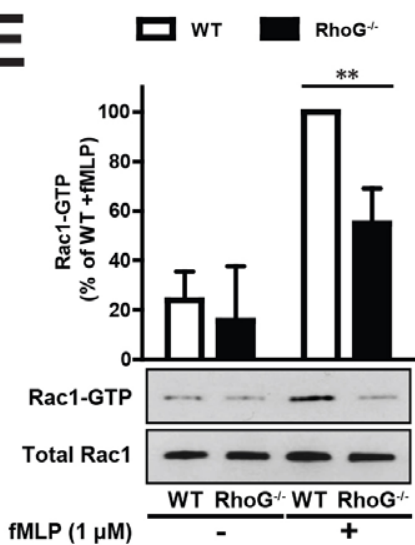

$\mathbf{G}$

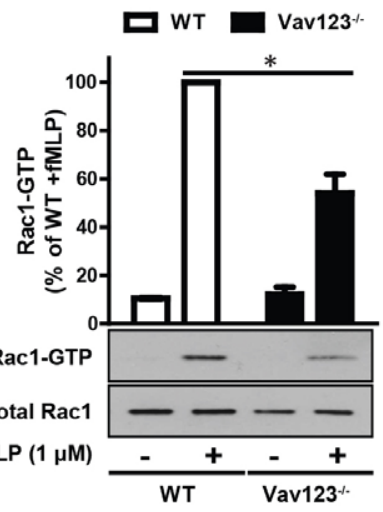

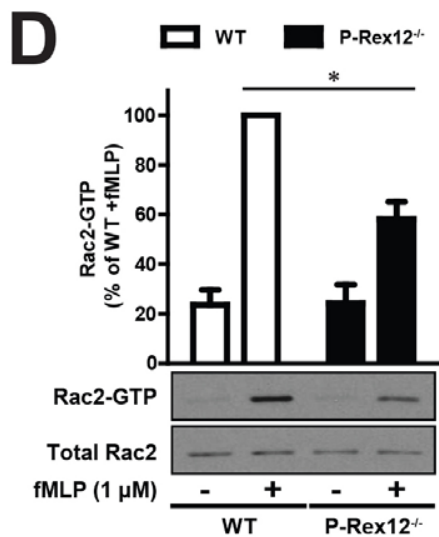

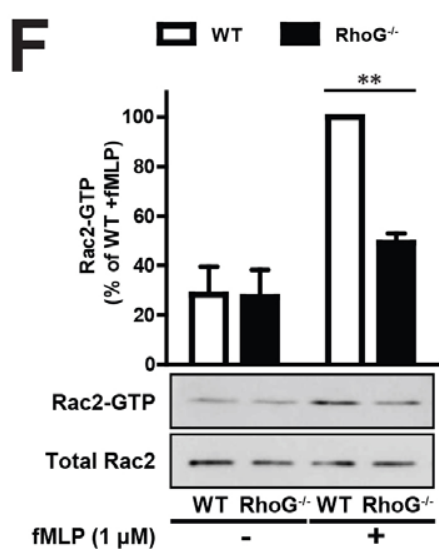

H

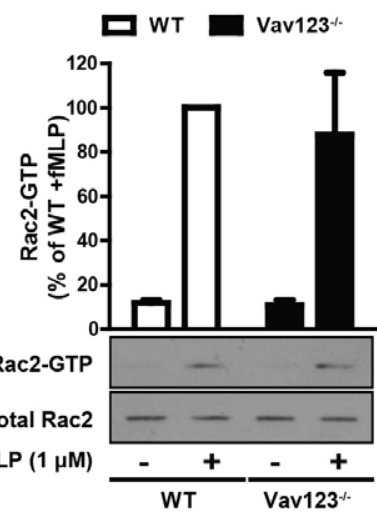

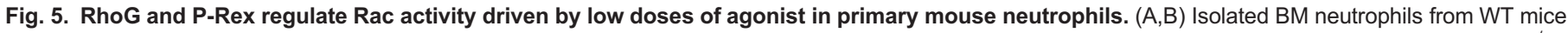

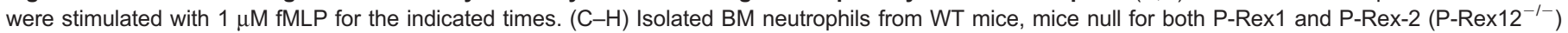
$(C, D)$, and $\mathrm{RhoG}^{-1-}$ mice $(\mathrm{E}, \mathrm{F})$ or mice null for all three Vav isoforms (Vav123 $\left.{ }^{-1-}\right)(\mathrm{G}, \mathrm{H})$ were stimulated with $1 \mu \mathrm{M}$ fMLP for $10 \mathrm{~s}$. Activation of Rac1

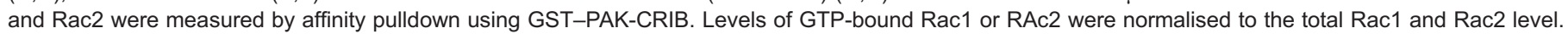

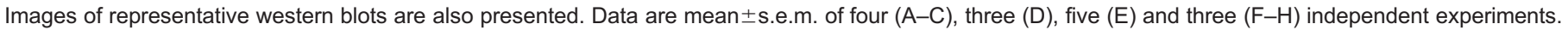
${ }^{*} P \leq 0.05,{ }^{*} P \leq 0.01$ by an unpaired Student's $t$-test.

\section{RhoG regulates fMLP-driven polarisation of F-actin}

Neutrophils from DOCK $2^{-/-}$mice exhibit a profound defect in their ability to concentrate F-actin at the leading edge upon treatment with fMLP (Kunisaki et al., 2006), presumably due to the loss of Rac activity that would normally be localised to this region. This spontaneous polarisation appears to be independent of agonist gradients, and follows a rapid global spike in actin polymerisation that is unaffected by loss of DOCK2. Given that our data suggest that RhoG can act as an upstream regulator of DOCK2-driven Rac activity, we visualised the distribution of
F-actin in fMLP-stimulated neutrophils to assess whether loss of RhoG affects this polarisation process. Cells were stimulated in suspension, to allow spontaneous polarisation, then fixed and stained with TRITC-phalloidin, allowing us to visualise and calculate the distribution of $\mathrm{F}$-actin by wide-field epifluorescence microscopy (Fig. 7C,G). As in previous studies of this process, rapid actin polymerisation ( $\sim 15 \mathrm{~s}$ post-fMLP treatment) could be visualised as a bright ring of phalloidin staining that marked out the entire cell perimeter. Consistent with a previously reported lack of effect of DOCK2, this event 
A

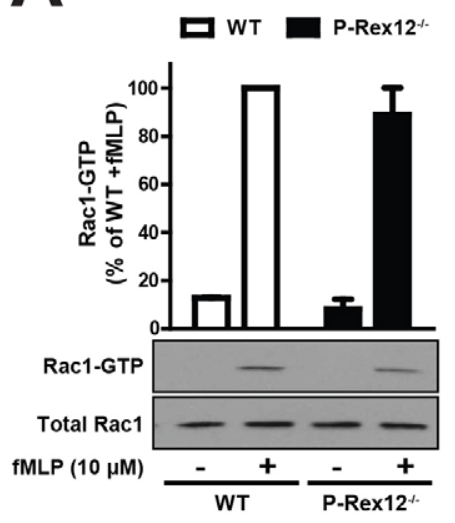

C

D WT RhoG $*$

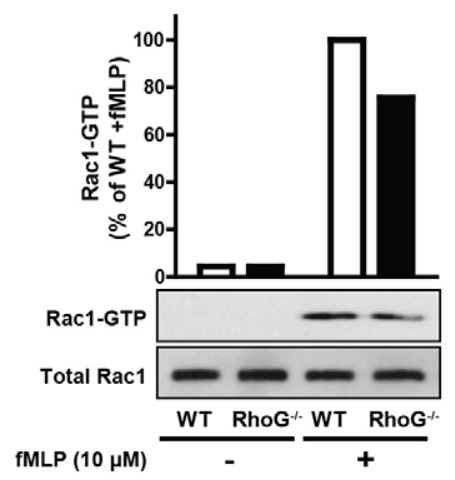

E

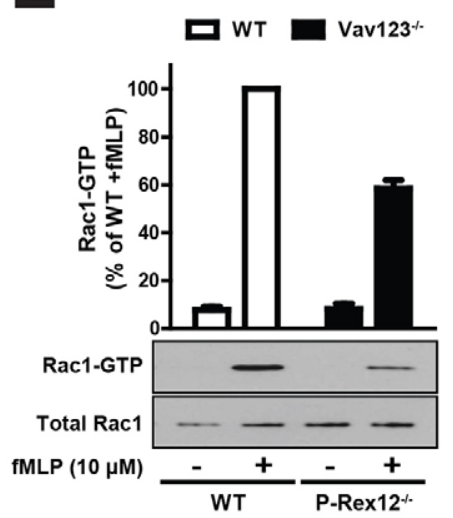

B

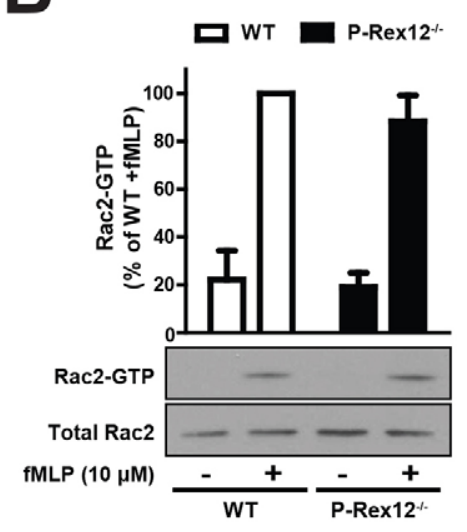

D

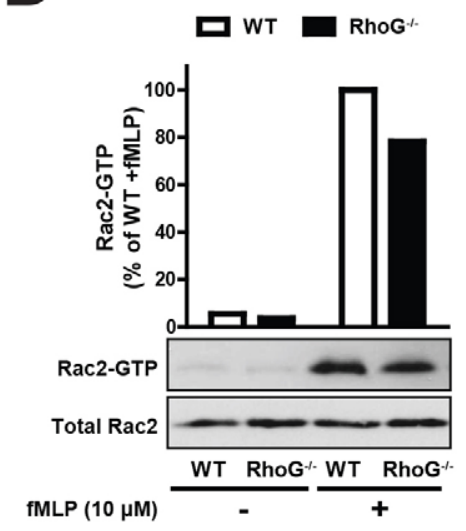

$\mathbf{F}$

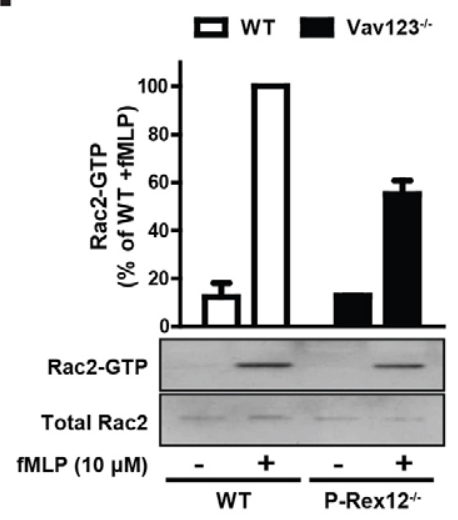

Fig. 6. Effect of Vav deletion on Rac activity predominates at high doses of agonist. Isolated BM neutrophils from WT mice and mice null for both P-Rex1 and P-Rex-2 (P-Rex12 ${ }^{-/-}$) $(A, B), R_{h o G}^{-l-}$ mice $(C, D)$ or mice null for all three Vav isoforms $\left(\operatorname{Vav} 123^{-1-}\right)(E, F)$ were stimulated with $10 \mu \mathrm{M}$ fMLP for $10 \mathrm{~s}$. Activation of Rac1 and Rac2 were measured by affinity pulldown using GST-PAK-CRIB. Levels of GTP-bound Rac1 or Rac2 were normalised to the total Rac1 and Rac2 level. Images of representative western blots are also presented. Data are mean \pm range of two $(A, B, E, F)$ independent experiments. was unaffected by RhoG deletion. FACS analysis of total cellular F-actin levels also confirmed that loss of RhoG does not significantly curtail global fMLP-driven actin polymerisation (Fig. 7D). Polarisation of F-actin began at $\sim 30 \mathrm{~s}$ and was largely complete by $2 \mathrm{~min}$. At 1 and $2 \mathrm{~min}$, both the number of cells exhibiting F-actin polarisation, and the extent of F-actin polarisation, were significantly reduced in $\mathrm{RhoG}^{-/-}$neutrophils compared to WT neutrophils (Fig. 7E,F). These results are consistent with a role for RhoG in controlling the localisation and activity of DOCK2 during fMLP-mediated neutrophil polarisation.

\section{DISCUSSION}

GPCRs elicit rapid changes in cell behaviour by modulating the activity of, and interplay between, multiple small GTPases, particularly those of the Rho family. The study of rapid GTPase regulation is central to our understanding of dynamic cellular processes, such as actin remodelling, secretion and redox signalling.

Our data reveal RhoG activation as a rapid and crucial event in GPCR-driven neutrophil function, and identify P-Rex1 as the major GEF responsible for guanine nucleotide exchange on RhoG in this system. This is the first study to successfully 


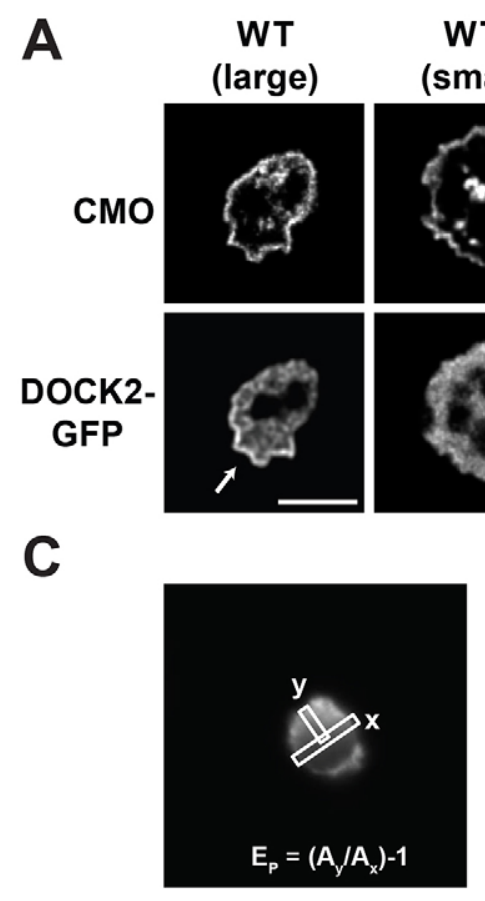

E

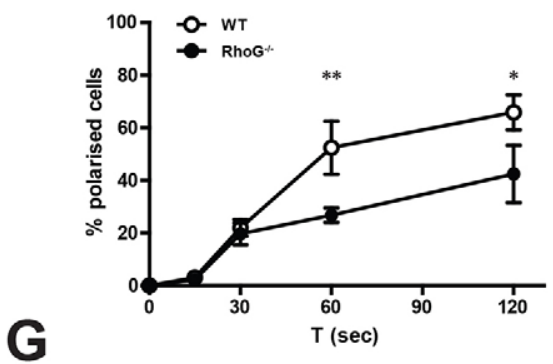

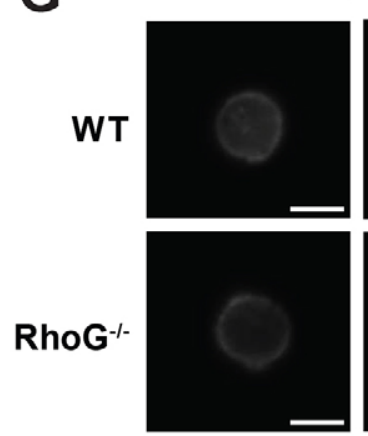

C
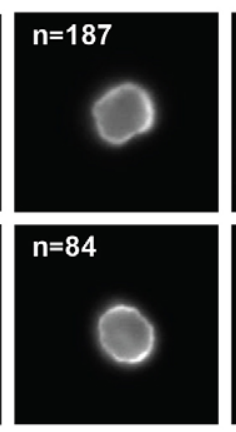

15s

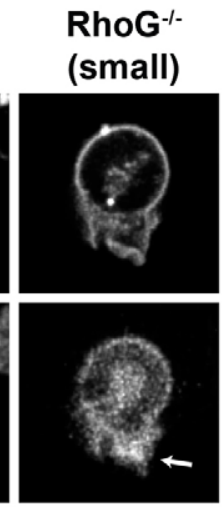

B

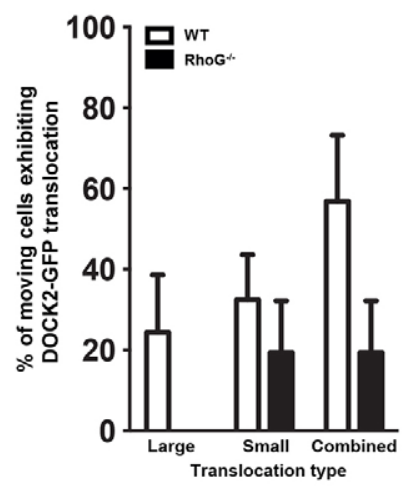

D
Fig. 7. RhoG regulates fMLP-induced DOCK2 translocation and F-actin polarisation to the leading edge of primary mouse neutrophils. $(A, B)$ Neutrophils from DOCK2-GFP-expressing control (WT) and $\mathrm{RhoG}^{-1-}$ mice were pre-labelled with the membrane dye $\mathrm{CMO}$, stimulated with $10 \mu \mathrm{M}$ fMLP and imaged by confocal microscopy. Representative images of 'large' and 'small' DOCK2-GFP translocation events in WT and RhoG $^{-1-}$ neutrophils are shown (A). Note that no 'large' translocation events were observed in neutrophils from RhoG ${ }^{-1-}$ mice. Events in neutrophils from five WT and three RhoG $^{-1}$ mice (average 11 cells per mouse) were counted and presented as pooled data (B). Data are mean \pm s.e.m. (C) Diagrammatic illustration of polarisation efficiency $\left(E_{P}\right)$ calculation. $E_{P}$ was determined as the ratio of mean fluorescence intensity (MFI) at the front versus the sides of each cell $\left(A_{y} / A_{x}\right)-1$. (D) Neutrophils from WT and RhoG ${ }^{-1-}$ mice were stimulated with $10 \mu \mathrm{M}$ fMLP for the indicated times before being fixed, permeabilised and stained with TRITCphalloidin. Total F-actin levels, measured by flow cytometry, are presented as MFI. Data are mean \pm s.e.m. of three independent experiments performed in duplicate. (E-G) Neutrophils from WT and RhoG ${ }^{-1-}$ mice were stimulated with $10 \mu \mathrm{M}$ fMLP for the indicated times before being fixed, permeabilised, stained with TRITC-phalloidin and imaged by wide-field epifluorescence microscopy. The percentage of cells deemed to have polarised (defined as confinement of $\mathrm{F}$ actin to less than $50 \%$ of cell circumference) is presented $(E)$, along with the quantified polarisation efficiency $(F)$. Images of representative cells, from each stage of analysis, are presented $(G)$ along with the number of cells $(n)$ analysed at each stage. Data are mean \pm s.e.m. of three independent experiments. ${ }^{*} P \leq 0.05,{ }^{*} P \leq 0.01$ by an unpaired Student's $t$-test. Scale bars: $\sim 5 \mu \mathrm{m}$.
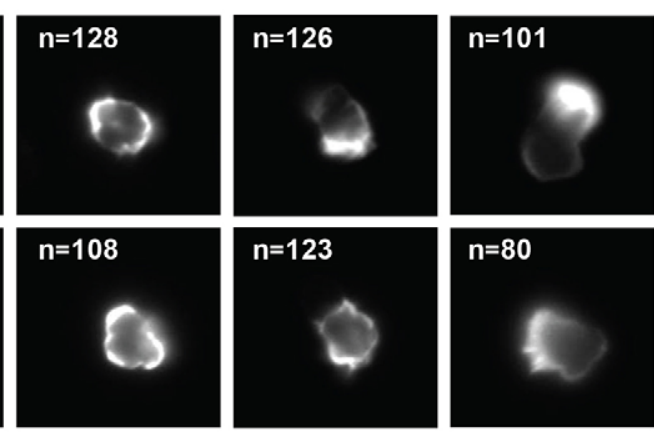

$30 \mathrm{~s}$

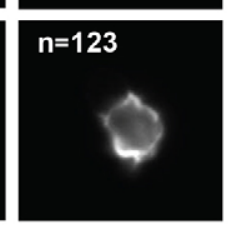

$60 s$

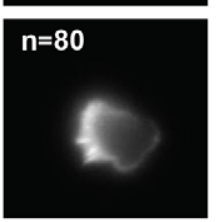

$120 \mathrm{~s}$ measure RhoG activation downstream of GPCRs, and both the speed of this response and its strong dependence on $\mathrm{PI} 3 \mathrm{~K} \gamma$ and P-Rex1 indicate a proximal relationship to receptor activation. Thus previous work has demonstrated synergistic regulation of P-Rex by $\beta \gamma$ subunits of $\mathrm{G}$ proteins (derived from Gi) and $\operatorname{PtdIns}(3,4,5) \mathrm{P}_{3}$ (derived from $\mathrm{G} \beta \gamma$-stimulated PI3K $\gamma$ ) (Barber et al., 2007; Hill et al., 2005; Welch et al., 2002).

It has been widely reported in other systems that RhoG can signal to Rac by recruiting DOCK proteins through their adaptor ELMO (Hiramoto et al., 2006; Katoh and Negishi, 2003). The striking defect we observed in DOCK2 recruitment to the leading edge of polarised neutrophils upon loss of RhoG indicates that this mechanism is also responsible for linking RhoG and Rac downstream of GPCRs in neutrophils. It is also consistent with previous data indicating P-Rex ${ }^{-l-}$ (Dong et al., 2005; Welch et al., 2005), $\mathrm{RhoG}^{-/-}$(Condliffe et al., 2006) and DOCK2 $2^{-1-}$ (Kunisaki et al., 2006) neutrophils all display defects in GPCRinduced Rac activity and ROS production. This new pathway for GPCR-mediated control of Rac thus unifies a number of confusing observations in the field of Rho family signalling, by indicating a hierarchical, rather than simply cooperative organisation of GEF input into Rac activation (Fig. 8). This pathway plays an important role in total cellular Rac activation at lower doses of agonist and is important for GPCR-stimulated ROS formation and actin polarisation. 


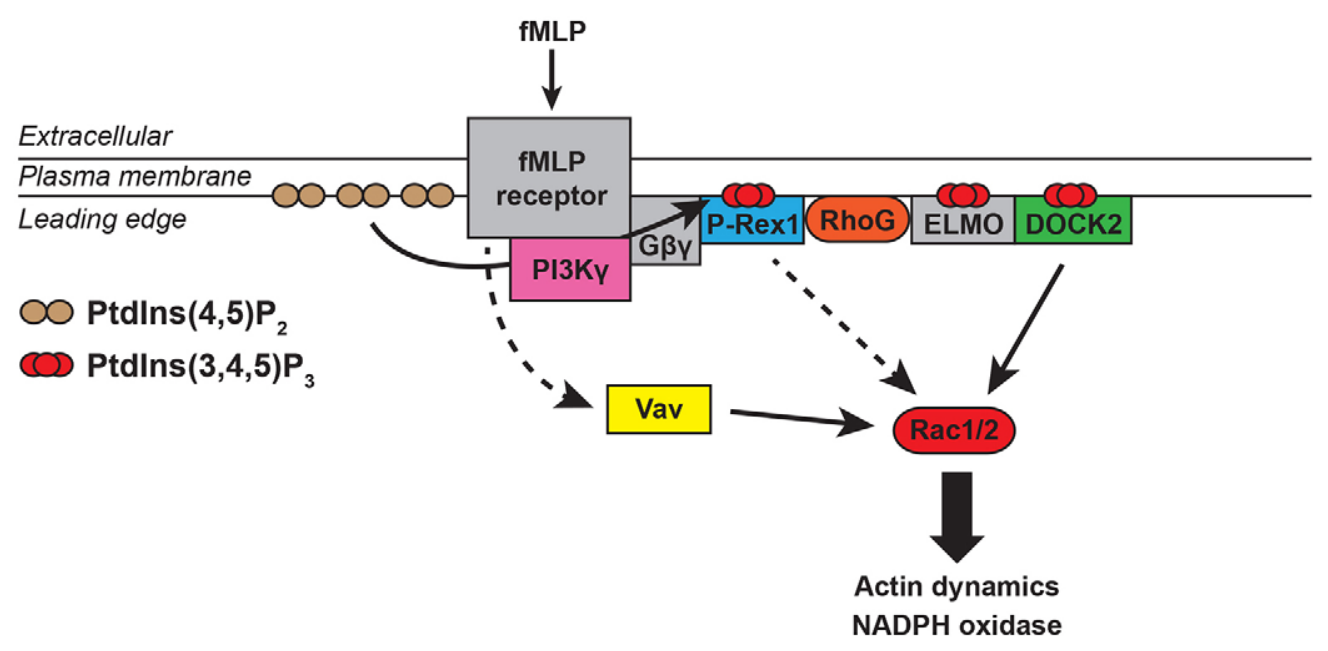

Fig. 8. Activation of Rac by the fMLP receptor in mouse neutrophils. Activation of the Gi-coupled GPCR for fMLP releases $G \beta \gamma$ subunits, which then synergise with $\mathrm{PI} 3 \mathrm{~K} \gamma$-generated Ptdlns $(3,4,5) P_{3}$ to activate P-Rex1, resulting in the formation of GTP-RhoG and RhoG-dependent activation of the Rac GEF DOCK2. Ptdlns $(3,4,5) P_{3}$ has also been shown to localise the ELMODOCK2 complex to the leading edge of neutrophils and, thus, has multiple inputs into the localisation of Rac activity. The bold arrows represent a direct regulatory input, the broken arrows represent an indirect or less certain regulatory input.
Our data also raise important questions about the more general role of P-Rex proteins in cells, and challenge the widely held view that P-Rex acts exclusively on Rac. The broad substrate selectivity of P-Rex in vitro actually suggests that several Rhofamily GTPases (including Rac and Cdc42) might be potential substrates for P-Rex in cells. However, given that RhoG functions upstream of Rac in a variety of systems (Blangy et al., 2000; Hiramoto et al., 2006; Katoh and Negishi, 2003), many (if not all) observations of P-Rex-dependent Rac activity could potentially be driven by the signalling hierarchy revealed here. In particular, given the recent interest in the role of both P-Rex and DOCK family members in cancer (Berger et al., 2012; Fine et al., 2009; Hodis et al., 2012; Lindsay et al., 2011; Sanz-Moreno et al., 2008; Sosa et al., 2010), it will be important to establish in this context whether RhoG is responsible for linking these two GEF families in a common pathway to Rac activation.

Many seminal studies of GEF and GTPase function have relied on overexpression systems using constitutively active or dominant-negative mutants, which might not always reflect events at the endogenous level. In the present study, we made use of the acute GPCR-sensitivity of primary neutrophils, which allowed us to measure activation of endogenous GTPases and assess the involvement of upstream regulators through their genetic deletion in mice. In addition, this approach provides further clarity in the interpretation of data on several fronts. First, GTPase activation events happen within a few seconds, rather than minutes, hours or days, reducing the probability that our measurements reflect convoluted homeostatic responses to cell stimulation, such as well-documented feedback loops (Stephens et al., 2008). Second, stimulation of quiescent neutrophils in suspension allowed us to measure at least some GPCR-driven signalling events (GTP-RhoG and -Rac, and ROS formation) with precision and in isolation, with minimal interference from background signals generated by autocrine or paracrine factors and/or adhesion to tissue culture plate surfaces. Even within this relatively simple context, it is clear that the organisation of Rac activation downstream of GPCRs is complex, involving both the P-Rex1-RhoG-DOCK2 pathway described here, parallel activation of Vav family GEFs (Turner and Billadeau, 2002) and, possibly, other pathways of DOCK2 activation [in this regard an analogous DOCK180-ELMO complex has recently been shown to be activated directly by $G \beta \gamma$ subunits in fibroblasts (Fritsch et al., 2013)]. The additional properties conveyed by this type of organisation (involving multiple inputs into the same GEF and, also, multiple GEFs) are still unclear, but they are likely to include both amplification of pathways to Rac (conveying sensitivity) and, through the specific molecular properties of the constituents, the coupling of Rac to molecular processes that are distinct to each particular Rac GEF involved (conveying specificity). The idea that GEFs are recruited into different molecular complexes, the composition of which depends on the precise context of cell stimulation, also naturally provides a mechanism whereby P-Rex, and indeed many other GEFs acting on Rho family GTPases, exhibit broad substrate specificity in vitro, but can be directed to different specific substrates in cells. It also allows a simple mechanism for the 'streaming' of pools of GTP-Rac to specific effectors, such as the NADPH oxidase. This picture, however, is still largely based on deduction, and a clear challenge for future studies in this field is to directly observe distinct GEF-GTPase interactions at the endogenous level, in a manner that appreciates their spatial and temporal specificity.

\section{MATERIALS AND METHODS}

\section{Animals}

$\mathrm{RhoG}^{-1-}$ mice (Vigorito et al., 2004) on a mixed C57BL/6J $\times 129 / \mathrm{Sv}$ background were selected, by PCR genotyping, from litters born to heterozygous parents. WT littermates were used as controls where possible. PI3K $\gamma^{-1-}$ mice on a 129/Ola background were obtained as described previously (Hirsch et al., 2000) and WT controls were bred in parallel. Mice null for all three Vav isoforms $\left(\operatorname{Vav} 123^{-/-}\right.$) on a B10/Br background were generated by breeding $\mathrm{Vav1}^{-/-}$, $\mathrm{Vav}^{-1-}$ and $\mathrm{Vav} 3^{-1-}$ mice as described previously (Fujikawa et al., 2003) and WT B10Br mice were used as controls. P-Rex $1^{-1-}$ mice and mice null for both P-Rex 1 and $\mathrm{P}-\mathrm{Rex} 2\left(\mathrm{P}-\mathrm{Rex} 12^{-/-}\right)$on a mixed C57BL/6J $\times 129 / \mathrm{Sv}$ background were obtained as described previously (Donald et al., 2008; Welch et al., 2005) and WT controls were bred in parallel. Rac2 $2^{-1-}$ mice on a C57BL/6J background were obtained as described previously (Roberts et al., 1999) and WT C57BL/6 mice were obtained from the Babraham Institute Biological Services Breeding Unit for use as controls. Mice were used at between 8-20 weeks of age and age-matched where possible. $\mathrm{RhoG}^{-/-}$, $\mathrm{PI} 3 \mathrm{~K} \gamma^{-1-}, \mathrm{P}-\mathrm{Rex} 1^{-/-}$, P-Rex $12^{-/-}$and associated WT control mice were housed in individually ventilated cages in a barriered animal facility. Vav123 $3^{-1-}, \operatorname{Rac}^{-1-}$ and associated WT control mice were housed in the same facility but within isolators under specific opportunistic pathogenfree conditions. DOCK2-GFP mice (Kunisaki et al., 2006) on a C57BL/6J background were bred with $\mathrm{RhoG}^{-/-}$for at least two generations and DOCK2-GFP $\times \mathrm{RhoG}^{-1-}$ used for experiments along with DOCK2-GFP $\times \mathrm{RhoG}^{+/+}$littermates as controls. All mouse work was submitted to and approved by the Animal Welfare Ethics Committee at the Babraham Institute under Home Office Project License PPL 80/2335. 


\section{Isolation and preparation of primary neutrophils from mouse bone marrow}

For measurements of PtdIns $(3,4,5) P_{3}$ and Rac-GTP levels, mouse bone marrow was suspended in HBSS (without $\mathrm{Ca}^{2+}$ and $\mathrm{Mg}^{2+}$ ), supplemented with $15 \mathrm{mM}$ HEPES and $0.25 \%$ endotoxin/fatty acid free BSA (HBSS++), and centrifuged ( $326 \mathrm{~g}$ at room temperature). Cells were re-suspended and separated by centrifugation ( $1640 \mathrm{~g}$ at room temperature) for $30 \mathrm{~min}$ on discontinuous gradients comprising 62\% and 55\% Percoll (Amersham). Neutrophils ( $70-95 \%$ pure, assessed by cytospin) were harvested from the $62 \%-55 \%$ interface and remaining erythrocytes removed by ammonium chloride lysis $\left(130 \mathrm{mM} \mathrm{NH} \mathrm{Nl}_{4} \mathrm{Cl} 5 \mathrm{mM} \mathrm{KCl}, 0.78 \mathrm{mM} \mathrm{Na}_{2} \mathrm{HPO}_{4}\right.$, $0.176 \mathrm{mM} \mathrm{KH}_{2} \mathrm{PO}_{4}, 5.5 \mathrm{mM}$ glucose, $1 \mathrm{mM} \mathrm{MgCl} 2,0.28 \mathrm{mM} \mathrm{MgSO}_{4}$, $1.54 \mathrm{mM} \mathrm{CaCl}_{2}, 13.4 \mathrm{mM} \mathrm{NaHCO}$ ) for $1-2 \mathrm{~min}$. Cells were washed twice with HBSS++ and once with Dulbecco's PBS containing $\mathrm{Ca}^{2+}$ and $\mathrm{Mg}^{2+}$, supplemented with $1 \mathrm{~g} / 1$ glucose and $4 \mathrm{mM} \mathrm{NaHCO}_{3}$ (D-PBS++), and re-suspended in an appropriate volume of D-PBS++ depending on the assay. Where possible, bone marrow from two or more mice (per genotype) was combined to reduce variation between individual mice. Each pooled preparation was treated as an independent experiment (see figure legends).

For measurements of RhoG-GTP, Cdc42-GTP, F-actin and ROS levels and DOCK2 translocation, we refined our neutrophil isolation procedures to reduce basal activation by autocrine and/or paracrine factors, which we found necessary to obtain a reproducible measure of GTP-RhoG in resting cells. Mouse bone marrow was suspended in ice cold HBSS++ and separated by centrifugation $\left(1640 \mathrm{~g}\right.$ at $\left.4^{\circ} \mathrm{C}\right)$ for $30 \mathrm{~min}$ on discontinuous gradients comprised of HBSS++ and 58\% Percoll. Nongranulocytic leukocytes were removed from the HBSS++-Percoll interface and erythrocytes removed by ammonium chloride lysis. Cells (60-80\% pure, assessed by cytospin) were then washed once (326 $g$ at $4^{\circ} \mathrm{C}$ ) in HBSS++ and re-suspended at $1 \times 10^{7} / \mathrm{ml}$ in D-PBS ++ . Cell suspensions were incubated for $2 \mathrm{~min}$ at $37^{\circ} \mathrm{C}$ prior to stimulation except where treatment with inhibitors was required. Inhibitor treatments were all performed at $37^{\circ} \mathrm{C}$ as follows: $100 \mathrm{nM}$ wortmannin for $5 \mathrm{~min}, 20 \mu \mathrm{g}$ / $\mathrm{ml}$ Latrunculin B for $10 \mathrm{~min}$.

\section{Measurement of endogenous PtdIns $(3,4,5) P_{\mathbf{3}}$ levels}

Mouse primary neutrophils, isolated as described above, were equilibrated to $37^{\circ} \mathrm{C}$ and $1 \times 10^{6}$ cells stimulated with $10 \mu \mathrm{M}$ fMLP for the indicated periods of time. Cells were then lysed, and lipids extracted, derivatised and analysed by LC-ESI/MS as described previously (Clark et al., 2011).

\section{Measurement of endogenous RhoG, Rac1 and Rac2 activity}

Mouse primary neutrophils $\left(1 \times 10^{7}\right.$ cells $/ \mathrm{ml}$ in D-PBS++) were equilibrated to $37^{\circ} \mathrm{C}$ and $2 \times 10^{6}$ cells stimulated, with indicated concentrations of fMLP or C5a, and incubated at $37^{\circ} \mathrm{C}$ for the periods of time described. Cells were suspended in a $1 \mathrm{ml}$ final volume of icecold GST-FISH buffer (10\% glycerol, $50 \mathrm{mM}$ Tris-HCl pH 7.4, $100 \mathrm{mM}$ $\mathrm{NaCl}, 1 \% \mathrm{NP} 40,2 \mathrm{mM} \mathrm{MgCl}_{2}, 20 \mathrm{mM} \mathrm{NaF}$ ) and incubated for $3 \mathrm{~min}$ on ice. Lysates were centrifuged $\left(13,000 \mathrm{~g}\right.$ for $3 \mathrm{~min}$ at $\left.4^{\circ} \mathrm{C}\right)$ and $50 \mu \mathrm{l}$ aliquots taken to assess total levels of RhoG or Rac. A $750 \mu$ volume of the remaining supernatant was added to $20 \mu 1$ of glutathione-Sepharose4B beads, containing approximately $20-50 \mu \mathrm{g}$ of GST-ELMO1 (for detection of GTP-RhoG) or GST-PAK-CRIB (for detection of GTPbound Rac1 and Rac2), and incubated with rotation for 15 min at $4{ }^{\circ} \mathrm{C}$. Beads were washed three times in GST-FISH buffer and suspended in Laemmli sample buffer. Samples were separated by $12 \%$ SDS-PAGE and analysed by western blotting.

\section{Guanine-nucleotide-exchange assays}

A cDNA fragment encoding the DH-PH domains of P-Rex1 (residues 40-405) was subcloned into the vector pProEx HTb (Invitrogen) in frame with an $\mathrm{N}$-terminal $\mathrm{His}_{6}$ tag. P-Rex1 DH-PH protein was expressed in Rosetta2 BL21 (DE3) E. coli cells (EMD Biosciences) grown in lysogeny broth (LB) with AMP and induced with $0.2 \mathrm{mM}$ IPTG for $16 \mathrm{~h}$ at $20^{\circ} \mathrm{C}$ before being purified using a 5-ml HisTrap Fast Flow column (GE Healthcare). P-Rex1-containing fractions were incubated with tobacco etch virus protease overnight to release the $\mathrm{His}_{6}$ tag and subsequently loaded onto an S-200 size exclusion column (GE Healthcare) equilibrated in $20 \mathrm{mM}$ Tris- $\mathrm{HCl} \mathrm{pH} 8.0,200 \mathrm{mM} \mathrm{NaCl}, 1 \mathrm{mM}$ EDTA, 2 mM DTT and $10 \%$ glycerol. Fractions containing purified P-Rex1 DH-PH protein were pooled, concentrated, snap frozen in liquid N2 and stored at $-80^{\circ} \mathrm{C}$. His $_{6}$-tagged RhoGTPases were expressed and purified as described previously (Mitin et al., 2007).

$\mathrm{N}$-methylanthraniloyl (mant)-GTP incorporation into bacterially expressed and purified RhoGTPases was carried out with a FluoroMax4 spectrometer (Horiba) at $20^{\circ} \mathrm{C}$ as described previously (Mitin et al., 2007). Exchange-reaction assay mixtures containing $20 \mathrm{mM}$ Tris- $\mathrm{HCl}$ pH 7.5, $200 \mathrm{mM} \mathrm{NaCl}, 5 \mathrm{mM} \mathrm{MgCl}_{2}, 1 \mathrm{mM}$ DTT, 5\% (v/v) glycerol, $400 \mathrm{nM}$ mant-GTP (Invitrogen) and $2 \mu \mathrm{M}$ of the relevant GTPase were prepared and allowed to equilibrate with continuous stirring. After equilibration, P-Rex1 DH-PH protein was added at $200 \mu \mathrm{M}$ and the fluorescence intensity $\left(\lambda_{\text {emission }}, 360 \mathrm{~nm} ; \lambda_{\text {excitation }}, 440 \mathrm{~nm}\right)$ was monitored.

An alternative, immunoprecipitation-based assay was also performed in a small number of experiments using recombinant full-length EEtagged P-Rex1 (purified from baculovirus-infected Sf9 cells) and $\left[{ }^{35} \mathrm{~S}\right] \mathrm{GTP} \gamma \mathrm{S}$-loading of EE-tagged, lipid-modified RhoG (purified from baculovirus-infected Sf9 cells using Triton X114), as described previously (Welch et al., 2002).

\section{Measurement of neutrophil NADPH oxidase activity}

ROS production by WT and $\mathrm{RhoG}^{-/-}$mouse neutrophils was measured by luminol-dependent chemiluminescence in a plate luminometer, as described previously (Condliffe et al., 2005). Mouse neutrophils $\left(2.5 \times 10^{6}\right.$ cells $/ \mathrm{ml}$ in D-PBS++ at $37^{\circ} \mathrm{C}$ ) were incubated with $160 \mu \mathrm{M}$ Luminol in the presence of $26.7 \mathrm{U} / \mathrm{ml}$ horseradish peroxidase (HRP). Samples were assayed in duplicate and treated as technical replicates.

\section{Measurement of total and polarised F-actin accumulation}

Mouse neutrophils were isolated at $4^{\circ} \mathrm{C}$, suspended (at $5 \times 10^{6}$ cells $/ \mathrm{ml}$ ) in D-PBS++ with $0.1 \%$ BSA and equilibrated for $2 \mathrm{~min}$ at $37^{\circ} \mathrm{C} .10^{6}$ cells per sample were stimulated, for the indicated periods of time, with $10 \mu \mathrm{M}$ fMLP and fixed in an equal volume of $4 \%$ paraformaldehyde $(2 \%$ final) for $15 \mathrm{~min}$ at room temperature. Fixed cells were diluted in an excess volume of D-PBS++ with $0.1 \%$ BSA, centrifuged (500 $g$ for $4 \mathrm{~min}$ at room temperature) and supernatants discarded. Cells were resuspended in $1 \mathrm{ml} \mathrm{D-PBS}++/ 2 \% \quad \mathrm{BSA}$ and centrifuged again. Supernatants were discarded, cells re-suspended in $200 \mu \mathrm{l}$ staining buffer (D-PBS++/0.1\% BSA containing 1\% Triton X-100 and $50 \mathrm{ng} / \mathrm{ml}$ TRITC-phalloidin) and incubated for $15 \mathrm{~min}$ at room temperature. Cells were then washed twice in D-PBS++ with $2 \%$ BSA, suspended in $200 \mu 1$ PBS++ with $0.1 \%$ BSA and either imaged under wide-field epifluorescence (Olympus Cell ${ }^{\wedge} \mathrm{R}, 60 \times$ objective) or analysed on a FACSCalibur flow cytometer. Cells were scored for polarisation and polarisation efficiency (EP) was determined as described in Fig. 7.

\section{Imaging of DOCK2 translocation}

Mouse neutrophils were isolated at $4{ }^{\circ} \mathrm{C}$, suspended in D-PBS++ with $0.1 \% \mathrm{BSA}$ and incubated for $5 \mathrm{~min}$, on ice, in the presence of $1 \mu \mathrm{g} / \mathrm{ml}$ Cell Mask Orange (Invitrogen). After washing in D-PBS++, cells were pipetted onto the glass coverslip insert of an imaging ring and equilibrated to $37^{\circ} \mathrm{C}$ for $5 \mathrm{~min}$. Cells were then imaged for $7 \mathrm{~min}$, during which a $10 \mu \mathrm{M}$ fMLP was applied as a bath stimulation during the first minute of each movie. Images were acquired on a Nikon Ti-E confocal microscope with a Yokogawa CSU-10 spinning disk unit, and captured using an Andor iXon EM-CCD 897 camera. Raw image data were deconvolved using Huygens Professional software (SVI, Hilversum $\mathrm{NL})$.

\section{Acknowledgements}

We thank Keith Burridge for supplying the GST-ELMO1 construct and Keith Davidson, Suhasini Kulkarni, Jonathan Clark (BI mass spectrometry) and the team at the Babraham Biological Services Unit for their technical support. We also thank Simon Walker (BI Imaging Facility) for his assistance with DOCK2-GFP image capture and deconvolution. 
Competing interests

The authors declare no competing interests.

\section{Author contributions}

P.H. and L.S. conceived and supervised the project and co-wrote the manuscript; G.D. co-wrote the manuscript, designed, performed and analysed experiments; L.G. designed, performed and analysed experiments involving cells from DOCK2-GFP mice; K.R. designed, performed and analysed GEF assays of mant-GTP incorporation; C.L. performed GEF assays with full-length P-Rex; K.A. designed, performed and analysed PIP3 measurements; Y.F. supplied the DOCK2-GFP mice for the study; H.W. supplied the Vav123 $3^{-I-}, \mathrm{P}-\mathrm{Rex} 1^{-1}$ P-Rex $12^{-1-}$ and Rac2 ${ }^{-1-}$ mice for the study, and edited the manuscript; C.D. designed and supervised GEF assays of mant-GTP incorporation.

\section{Funding}

This work was supported by the Biotechnology and Biological Sciences Research Council (BBSRC) [programme grant number BB/J004456/1 and project grant number BB/1008489/1]; and the British Lung Foundation [grant number P05/1). G.D. and C.L. were each in receipt of a BBSRC PhD studentship. Deposited in PMC for release after 6 months.

\section{References}

Barber, M. A., Donald, S., Thelen, S., Anderson, K. E., Thelen, M. and Welch H. C. (2007). Membrane translocation of P-Rex1 is mediated by G protein betagamma subunits and phosphoinositide 3-kinase. J. Biol. Chem. 282, 29967-29976

Bass, M. D., Williamson, R. C., Nunan, R. D., Humphries, J. D., Byron, A., Morgan, M. R., Martin, P. and Humphries, M. J. (2011). A syndecan-4 hair trigger initiates wound healing through caveolin- and RhoG-regulated integrin endocytosis. Dev. Cell 21, 681-693.

Berger, M. F., Hodis, E., Heffernan, T. P., Deribe, Y. L., Lawrence, M. S., Protopopov, A., Ivanova, E., Watson, I. R., Nickerson, E., Ghosh, P. et al. (2012). Melanoma genome sequencing reveals frequent PREX2 mutations. Nature 485, 502-506.

Blangy, A., Vignal, E., Schmidt, S., Debant, A., Gauthier-Rouvière, C. and Fort, P. (2000). TrioGEF1 controls Rac- and Cdc42-dependent cell structures through the direct activation of rhoG. J. Cell Sci. 113, 729-739.

Brugnera, E., Haney, L., Grimsley, C., Lu, M., Walk, S. F., Tosello-Trampont, A. C., Macara, I. G., Madhani, H., Fink, G. R. and Ravichandran, K. S. (2002) Unconventional Rac-GEF activity is mediated through the Dock180-ELMO complex. Nat. Cell Biol. 4, 574-582.

Clark, J., Anderson, K. E., Juvin, V., Smith, T. S., Karpe, F., Wakelam, M. J., Stephens, L. R. and Hawkins, P. T. (2011). Quantification of PtdlnsP3 molecular species in cells and tissues by mass spectrometry. Nat. Methods $\mathbf{8}$, 267-272.

Condliffe, A. M., Davidson, K., Anderson, K. E., Ellson, C. D., Crabbe, T., Okkenhaug, K., Vanhaesebroeck, B., Turner, M., Webb, L., Wymann, M. P. et al. (2005). Sequential activation of class IB and class IA PI3K is important for the primed respiratory burst of human but not murine neutrophils. Blood 106, 1432-1440.

Condliffe, A. M., Webb, L. M., Ferguson, G. J., Davidson, K., Turner, M., Vigorito, E., Manifava, M., Chilvers, E. R., Stephens, L. R. and Hawkins, P. T. (2006). RhoG regulates the neutrophil NADPH oxidase. J. Immunol. 176, 5314-5320.

Côté, J. F. and Vuori, K. (2002). Identification of an evolutionarily conserved superfamily of DOCK180-related proteins with guanine nucleotide exchange activity. J. Cell Sci. 115, 4901-4913.

Côté, J. F., Motoyama, A. B., Bush, J. A. and Vuori, K. (2005). A novel and evolutionarily conserved Ptdlns(3,4,5)P3-binding domain is necessary for DOCK180 signalling. Nat. Cell Biol. 7, 797-807.

Dinauer, M. C. (2003). Regulation of neutrophil function by Rac GTPases. Curr. Opin. Hematol. 10, 8-15.

Donald, S., Hill, K., Lecureuil, C., Barnouin, R., Krugmann, S., John Coadwell, W., Andrews, S. R., Walker, S. A., Hawkins, P. T., Stephens, L. R. et al. (2004). P-Rex2, a new guanine-nucleotide exchange factor for Rac. FEBS Lett. 572, 172-176.

Donald, S., Humby, T., Fyfe, I., Segonds-Pichon, A., Walker, S. A., Andrews, S. R., Coadwell, W. J., Emson, P., Wilkinson, L. S. and Welch, H. C. (2008). P-Rex2 regulates Purkinje cell dendrite morphology and motor coordination. Proc. Natl. Acad. Sci. USA 105, 4483-4488.

Dong, X., Mo, Z., Bokoch, G., Guo, C., Li, Z. and Wu, D. (2005). P-Rex1 is a primary Rac2 guanine nucleotide exchange factor in mouse neutrophils. Curr. Biol. 15, 1874-1879.

Fine, B., Hodakoski, C., Koujak, S., Su, T., Saal, L. H., Maurer, M., Hopkins, B., Keniry, M., Sulis, M. L., Mense, S. et al. (2009). Activation of the PI3K pathway in cancer through inhibition of PTEN by exchange factor P-REX2a. Science 325, 1261-1265.

Fritsch, R., de Krijger, I., Fritsch, K., George, R., Reason, B., Kumar, M. S., Diefenbacher, M., Stamp, G. and Downward, J. (2013). RAS and RHO families of GTPases directly regulate distinct phosphoinositide 3-kinase isoforms. Cell 153, 1050-1063.

Fujikawa, K., Miletic, A. V., Alt, F. W., Faccio, R., Brown, T., Hoog, J., Fredericks, J., Nishi, S., Mildiner, S., Moores, S. L. et al. (2003). Vav1/2/3-null mice define an essential role for Vav family proteins in lymphocyte development and activation but a differential requirement in MAPK signaling in T and B cells. J. Exp. Med. 198, 1595-1608.

Hill, K., Krugmann, S., Andrews, S. R., Coadwell, W. J., Finan, P., Welch, H. C. E., Hawkins, P. T. and Stephens, L. R. (2005). Regulation of P-Rex1 by phosphatidylinositol $(3,4,5)$-trisphosphate and Gbetagamma subunits. J. Biol. Chem. 280, 4166-4173.

Hiramoto, K., Negishi, M. and Katoh, H. (2006). Dock4 is regulated by RhoG and promotes Rac-dependent cell migration. Exp. Cell Res. 312, 4205-4216.

Hiramoto-Yamaki, N., Takeuchi, S., Ueda, S., Harada, K., Fujimoto, S., Negishi, M. and Katoh, H. (2010). Ephexin4 and EphA2 mediate cell migration through a RhoG-dependent mechanism. J. Cell Biol. 190, 461-477.

Hirsch, E., Katanaev, V. L., Garlanda, C., Azzolino, O., Pirola, L., Silengo, L., Sozzani, S., Mantovani, A., Altruda, F. and Wymann, M. P. (2000). Central role for $\mathrm{G}$ protein-coupled phosphoinositide 3-kinase gamma in inflammation. Science 287, 1049-1053.

Ho, E., Irvine, T., Vilk, G. J., Lajoie, G., Ravichandran, K. S., D'Souza, S. J. and Dagnino, L. (2009). Integrin-linked kinase interactions with ELMO2 modulate cell polarity. Mol. Biol. Cell 20, 3033-3043.

Hodis, E., Watson, I. R., Kryukov, G. V., Arold, S. T., Imielinski, M., Theurillat, J. P., Nickerson, E., Auclair, D., Li, L., Place, C. et al. (2012). A landscape of driver mutations in melanoma. Cell 150, 251-263.

Hung, W. C., Chen, S. H., Paul, C. D., Stroka, K. M., Lo, Y. C., Yang, J. T. and Konstantopoulos, K. (2013). Distinct signaling mechanisms regulate migration in unconfined versus confined spaces. J. Cell Biol. 202, 807-824.

Katoh, H. and Negishi, M. (2003). RhoG activates Rac1 by direct interaction with the Dock180-binding protein Elmo. Nature 424, 461-464.

Kay, R. R., Langridge, P., Traynor, D. and Hoeller, O. (2008). Changing directions in the study of chemotaxis. Nat. Rev. Mol. Cell Biol. 9, 455-463.

Kim, C., Marchal, C. C., Penninger, J. and Dinauer, M. C. (2003). The hemopoietic Rho/Rac guanine nucleotide exchange factor Vav1 regulates $N$ formyl-methionyl-leucyl-phenylalanine-activated neutrophil functions. J. Immunol. 171, 4425-4430.

Kulkarni, K., Yang, J., Zhang, Z. and Barford, D. (2011). Multiple factors confer specific Cdc42 and Rac protein activation by dedicator of cytokinesis (DOCK) nucleotide exchange factors. J. Biol. Chem. 286, 25341-25351.

Kunisaki, Y., Nishikimi, A., Tanaka, Y., Takii, R., Noda, M., Inayoshi, A., Watanabe, K., Sanematsu, F., Sasazuki, T., Sasaki, T. et al. (2006). DOCK2 is a Rac activator that regulates motility and polarity during neutrophil chemotaxis. J. Cell Biol. 174, 647-652.

Lawson, C. D., Donald, S., Anderson, K. E., Patton, D. T. and Welch, H. C. (2011). P-Rex1 and Vav1 cooperate in the regulation of formyl-methionyl-leucylphenylalanine-dependent neutrophil responses. J. Immunol. 186, 1467-1476.

Li, Z., Jiang, H., Xie, W., Zhang, Z., Smrcka, A. V. and Wu, D. (2000). Roles of PLC-beta2 and -beta3 and PI3Kgamma in chemoattractant-mediated signal transduction. Science 287, 1046-1049.

Lindsay, C. R., Lawn, S., Campbell, A. D., Faller, W. J., Rambow, F., Mort, R. L., Timpson, P., Li, A., Cammareri, P., Ridgway, R. A. et al. (2011). P-Rex1 is required for efficient melanoblast migration and melanoma metastasis. Nat. Commun. 2, 555.

Lu, M., Kinchen, J. M., Rossman, K. L., Grimsley, C., deBakker, C., Brugnera, E., Tosello-Trampont, A. C., Haney, L. B., Klingele, D., Sondek, J. et al. (2004). PH domain of ELMO functions in trans to regulate Rac activation via Dock180. Nat. Struct. Mol. Biol. 11, 756-762.

Lu, M., Kinchen, J. M., Rossman, K. L., Grimsley, C., Hall, M., Sondek, J., Hengartner, M. O., Yajnik, V. and Ravichandran, K. S. (2005). A Stericinhibition model for regulation of nucleotide exchange via the Dock180 family of GEFs. Curr. Biol. 15, 371-377.

Mitin, N., Betts, L., Yohe, M. E., Der, C. J., Sondek, J. and Rossman, K. L. (2007). Release of autoinhibition of ASEF by APC leads to CDC42 activation and tumor suppression. Nat. Struct. Mol. Biol. 14, 814-823.

Nishihara, H., Maeda, M., Oda, A., Tsuda, M., Sawa, H., Nagashima, K. and Tanaka, S. (2002). DOCK2 associates with CrkL and regulates Rac1 in human leukemia cell lines. Blood 100, 3968-3974.

Nishikimi, A., Fukuhara, H., Su, W., Hongu, T., Takasuga, S., Mihara, H., Cao, Q., Sanematsu, F., Kanai, M., Hasegawa, H. et al. (2009). Sequential regulation of DOCK2 dynamics by two phospholipids during neutrophil chemotaxis. Science 324, 384-387.

Roberts, A. W., Kim, C., Zhen, L., Lowe, J. B., Kapur, R., Petryniak, B., Spaetti, A., Pollock, J. D., Borneo, J. B., Bradford, G. B. et al. (1999). Deficiency of the hematopoietic cell-specific Rho family GTPase Rac2 is characterized by abnormalities in neutrophil function and host defense. Immunity 10, 183196.

Rossman, K. L., Der, C. J. and Sondek, J. (2005). GEF means go: turning on RHO GTPases with guanine nucleotide-exchange factors. Nat. Rev. Mol. Cell Biol. 6, 167-180.

Samson, T., Welch, C., Monaghan-Benson, E., Hahn, K. M. and Burridge, K. (2010). Endogenous RhoG is rapidly activated after epidermal growth factor stimulation through multiple guanine-nucleotide exchange factors. Mol. Biol. Cell 21, 1629-1642.

Sanz-Moreno, V., Gadea, G., Ahn, J., Paterson, H., Marra, P., Pinner, S., Sahai, E. and Marshall, C. J. (2008). Rac activation and inactivation control plasticity of tumor cell movement. Cell 135, 510-523.

Sasaki, T., Irie-Sasaki, J., Jones, R. G., Oliveira-dos-Santos, A. J., Stanford, W. L., Bolon, B., Wakeham, A., Itie, A., Bouchard, D., Kozieradzki, I. et al. 
(2000). Function of PI3Kgamma in thymocyte development, T cell activation, and neutrophil migration. Science 287, 1040-1046.

Sosa, M. S., Lopez-Haber, C., Yang, C., Wang, H., Lemmon, M. A., Busillo, J. M., Luo, J., Benovic, J. L., Klein-Szanto, A., Yagi, H. et al. (2010). Identification of the Rac-GEF P-Rex1 as an essential mediator of ErbB signaling in breast cancer. Mol. Cell 40, 877-892.

Stephens, L., Milne, L. and Hawkins, P. (2008). Moving towards a better understanding of chemotaxis. Curr. Biol. 18, R485-R494.

Turner, M. and Billadeau, D. D. (2002). VAV proteins as signal integrators for multi-subunit immune-recognition receptors. Nat. Rev. Immunol. 2, 476-486.

van Buul, J. D., Allingham, M. J., Samson, T., Meller, J., Boulter, E., GarcíaMata, R. and Burridge, K. (2007). RhoG regulates endothelial apical cup assembly downstream from ICAM1 engagement and is involved in leukocyte trans-endothelial migration. J. Cell Biol. 178, 1279-1293.

Vigorito, E., Bell, S., Hebeis, B. J., Reynolds, H., McAdam, S., Emson, P. C., McKenzie, A. and Turner, M. (2004). Immunological function in mice lacking the Rac-related GTPase RhoG. Mol. Cell. Biol. 24, 719-729.

Welch, H. C., Coadwell, W. J., Ellson, C. D., Ferguson, G. J., Andrews, S. R., Erdjument-Bromage, H., Tempst, P., Hawkins, P. T. and Stephens, L. R. (2002). P-Rex1, a Ptdlns(3,4,5)P3- and Gbetagamma-regulated guaninenucleotide exchange factor for Rac. Cell 108, 809-821.

Welch, H. C. E., Condliffe, A. M., Milne, L. J., Ferguson, G. J., Hill, K., Webb, L. M. C., Okkenhaug, K., Coadwell, W. J., Andrews, S. R., Thelen, M. et al. (2005). P-Rex1 regulates neutrophil function. Curr. Biol. 15, 1867-1873. 